\title{
ESTUDIANTES BRASILEÑOS EN LA FACULTAD DE CIENCIAS MÉDICAS DE ROSARIO (ARGENTINA): IMPLICANCIAS INTERLINGÜISTICAS
}

\section{BRAZILIAN STUDENTS AT THE FACULTY OF MEDICAL SCIENCES OF ROSARIO (ARGENTINA): INTERLINGUISTIC IMPLICATIONS}

\section{Thalita Camargo Angelucci María Isabel Pozzo*}

\section{RESUMEN}

Globalmente, la migración estudiantil universitaria aumenta. En Latinoamérica, Argentina se destaca como epicentro de los intereses de extranjeros, especialmente en las carreras de Medicina. Brasil restringe el acceso a la universidad vía examen de ingreso. En los últimos años, el número de inscritos brasileños en la Facultad de Ciencias Médicas de la Universidad Nacional de Rosario (Santa Fe/Argentina) ha aumentado significativamente. Este fenómeno se presenta en la agenda de los medios de comunicación; sin embargo, los estudios académicos al respecto son escasos. Por esto, el objetivo de este estudio fue analizar las implicancias lingüísticas del fenómeno en relación a: a) la reciente política lingüística universitaria (exigencia de certificación en idioma español a ingresantes no hispanohablantes); b) la formación de comunidades lingüísticas cerradas; y c) el posicionamiento en un paradigma médico, que usa jerga propia. Partimos del marco teórico de la Sociolingüística (ROTAETXE AMUSATEGI, 1990), específicamente de las Políticas Lingüísticas (CALVET, 2007, ARNOUX, 2000), y adoptamos conceptos teórico-metodológicos del Análisis de Discurso (ORLANDI, 2015, 2011; PÊCHEUX, 1975/2016) para construir y analizar el siguiente corpus: documentos institucionales, noticias periodísticas y entrevistas semiestructuradas. De acuerdo a los tres objetivos propuestos, el análisis señala que: a) la aprobación en el examen de lengua española no garantiza el desarrollo expresivo en el contexto áulico, b) el fortalecimiento de la comunidad de brasileños interfiere en su apropiación del idioma español y c) no se constata dificultades lingüísticas sustanciales respecto a la apropiación de la jerga médica. A modo de conclusión, consideramos apremiante fortalecer las políticas lingüísticas

\footnotetext{
* Universidad Nacional de Rosario, Instituto Rosario de Investigaciones en Ciencias de la Educación Consejo Nacional de Investigaciones Científicas y Técnicas, Rosario, Argentina. angelucci@iriceconicet.gov.ar

Orcid: https://orcid.org/0000-0002-0158-7953

** Universidad Nacional de Rosario, Instituto Rosario de Investigaciones en Ciencias de la Educación - Consejo Nacional de Investigaciones Científicas y Técnicas, Rosario, Argentina.pozzo@iriceconicet.gov.ar

Orcid: https://orcid.org/0000-0003-0186-0910
} 
e interculturales universitarias volcadas al acogimiento de estudiantes extranjeros, sobre todo en el campo de la formación en Medicina.

Palabras clave: migración estudiantili políticas lingüísticas; Medicina.

\section{ABSTRACT}

Globally, university migration increases. In Latin America, Argentina stands out as the epicenter of the interests of foreigners, especially in medical careers. Brazil restricts access to the university through an entrance examination. In recent years, the number of Brazilian students in the Faculty of Medical Sciences of the National University of Rosario has increased significantly. This phenomenon is presented in the media agenda; however, academic studies are scarce. Therefore, it is aimed to analyze the linguistic implications of this phenomenon in relation to: a) the recent university language policy (require certification in Spanish to non-Spanish speakers); b) the formation of closed linguistic communities; and c) the positioning in a medical paradigm, which uses its own jargon. The study is based on the theoretical framework of Sociolinguistics (ROTAETXE AMUSATEGI, 1990), specifically on Linguistic Policies (CALVET, 2007; ARNOUX, 2000), and on theoreticalmethodological concepts of Discourse Analysis (ORLANDI, 2015, 2011; PÊCHEUX, 1975/2016) to build and analyze the following linguistic corpus: institutional documents, online news and semi-structured interviews. According to the three proposed objectives, the analysis indicates that: a) the approval in the Spanish language test does not guarantee the expressive development in the academic context, b) the strengthening of the Brazilian community interferes with its appropriation of the Spanish language and c) there are no substantial linguistic difficulties regarding the appropriation of medical jargon. It advocates strengthening university linguistic and intercultural policies aimed at fostering foreign students, especially in the field of medical training.

Keywords: student migration; linguistic policies; Medicine.

\section{INTRODUCCIÓN}

La presente investigación se enmarca en los estudios sociolingüísticos, que se ocupan de las relaciones entre lenguajes y sociedad, y que tomaron forma en la década de 1960 bajo la confluencia de tres disciplinas: antropología, sociología y lingüística. Mientras la lingüística estudia el sistema lingüístico, la sociolingüística enfoca la lengua como institución social. De acuerdo con Rotaetxe Amusategi (1990), la lengua es entendida como fenómeno social y, como tal, depende de decisiones sociales, ya sean de instituciones -aquí, la universidad-, ya sean de usuarios de la lengua. Estos dos tipos de decisiones confieren un sentido amplio al concepto políticas lingüísticas (ARNOUX, 2000). Sumándose a esto, la sociolingüística también se ocupa de dirimir las circunstancias de los intercambios lingüísticos. De ese modo, se interesa por los comportamientos sociales y lingüísticos que la norma -variable en el tiempo y en el espacio- provoca en los hablantes, ya sea con respecto a cómo juzgan su propia habla (valorizándola o intentando cambiarla para adecuarse a otro 
modelo), ya sea en función de las reacciones de los hablantes cuando escuchan a otros (juzgados de acuerdo a su modo de hablar) (CALVET, 2007).

Partiendo de estas premisas, este estudio se centra sobre las cuestiones interlingüísticas atravesadas por la comunidad académica de la Universidad Nacional de Rosario (UNR) a partir del reciente aumento de ingresantes no hispanohablantes -brasileños- en su Facultad de Ciencias Médicas (FCM).

A nivel global, asistimos a nuevos procesos migratorios que conducen a instancias tanto de contacto, como de conflicto entre lenguas y culturas. En lo que atañe a la inmigración de estudiantes universitarios latinoamericanos, Argentina se destaca como país receptor. Con ofertas públicas, de calidad y de acceso irrestricto, funciona como epicentro de los intereses de jóvenes y adultos aspirantes a estudios universitarios.

Brasil, a pesar de contar con universidades públicas y de calidad, impone un sistema de acceso con cupos limitados, que se completan vía examen de ingreso ${ }^{1}$ o Sistema de Selección Unificada ${ }^{2}$ ( $\mathrm{SiSU}$ ) que, a su vez, seleccionan candidatos a partir de un disputado orden de mérito. Tomando como ejemplo la Universidad de São Paulo (USP), observamos que Medicina lidera el ranking de carreras más concurridas. De acuerdo con el periódico en línea de la USP, en el vestibular 2018, la carrera de Medicina en el Campus de São Paulo contó con 135,7 candidatos por plaza, seguida de Medicina en el Campus de Bauru-SP, con 105,7 y Medicina en Ribeirão Preto-SP, con 86,5. A modo de comparación, en el décimo quinto lugar del referido ranking, se encuentra la carrera de Arquitectura en el Campus de São Carlos-SP con un índice mucho más bajo: 28,7 candidatos por plaza. La problemática en la educación superior pública brasileña se amplía con la situación en el ámbito privado. Los cursos de Medicina en universidades pagas se caracterizan por sus mensualidades dispendiosas: en la provincia de Rio de Janeiro, por ejemplo, una cuota estándar gira en torno de $\mathrm{R} \$ 8.500$. Esta suma es mucho mayor de lo que un estudiante extranjero necesita para vivir en Argentina.

Rosario es la tercera ciudad más poblada de Argentina, tiene grande importancia económica y cultural, y se ubica en la provincia de Santa $\mathrm{Fe}$, región central del país. Allí, la UNR fue creada en 1968 y cuenta hoy con 12 facultades que alojan 63 carreras de grado, entre otras ofertas académicas. En los últimos cinco años, se produjo en la universidad un notorio incremento del número de inscriptos

1. Traducción propia para vestibular.

2. Traducción propia para Sistema de Seleção Unificada.

3. Disponible en: http://jornal.usp.br/universidade/ingresso/fuvest-divulga-relacao-candidatovagapara-o-vestibular-usp-2018/. 
provenientes de países vecinos, particularmente de Brasil. Los brasileños ingresan, mayoritariamente, en las carreras de Medicina de las ciudades de Buenos Aires, Mar del Plata y Rosario, siendo esta última foco del presente estudio.

Este crecimiento del número de estudiantes brasileños viene siendo apreciado entre los miembros de la comunidad académica, en la experiencia cotidiana de la ciudad y en los medios de comunicación local (ARANDA, 2018; BARRANDEGUY, 2016; CARMO, 2018; COSTA y LACROZE, 2017; GAVIRA, 2017; LUCHILO, 2018; NARDONE, 2018). Sin embargo, mientras existen estudios en otras Facultades (UGARTECHE, RODRÍGUEZ y POZZO, 2012 para la Facultad de Psicología) o con otras nacionalidades (POZZO, 2014 para los haitianos en Medicina), los estudios académicos con la población referida son escasos.

Se viene observando una particular dificultad con el idioma local, a lo que se suma el lenguaje específico referente a la jerga médica (BUYSE y POZZO, 2008). Por estas y otras razones, la UNR ha implementado una política lingüística oficializada en la Ordenanza $N^{\circ} 728$ (2017) de su Consejo Superior, que exige a los estudiantes no hispanohablantes la acreditación del nivel intermedio independiente (B2) de conocimiento de la lengua española, de acuerdo con los parámetros establecidos en el Marco Europeo Común de Referencia para las Lenguas (CONSEJO DE EUROPA, 2002).

En ese contexto, el objetivo general del estudio fue analizar las implicancias interlingüísticas del aumento del número de inscriptos brasileños en la FCM de la UNR en los últimos cinco años (2013-2018). Específicamente, pretendimos relacionar dicho fenómeno con:

a) en el nivel institucional: la nueva política lingüística universitaria;

b) en el nivel socio-subjetivo: la influencia de la formación de comunidades lingüísticas en la apropiación de la lengua meta; y

c) en el nivel académico-profesional: la necesidad de posicionarse en un paradigma médico, con su jerga propia, en una lengua extranjera.

Si bien la organización de los objetivos específicos en tres niveles fue operativa para llevar a cabo la investigación, resaltamos que los mismos se encuentran estrechamente vinculados.

Trabajamos con dos hipótesis respecto a las relaciones interlingüísticas imbricadas con el ascenso del número de brasileños. Primero, consideramos que cuanto menor el número de extranjeros en determinado territorio, mayor la necesidad de apropiarse de la lengua-cultura de inmersión como estrategia de supervivencia. Cuando aumenta el número de estos migrantes, se potencia la formación de 
comunidades endógenas, en las que se busca reproducir la vida del país de origen en la comunidad de destino, hecho que influye en la incorporación de la nueva lengua. Efectivamente, este modus operandi, en el que la inmigración se configura como problema de política lingüística, ha ocurrido en gran escala en Argentina entre fines del siglo XIX y comienzos del XX, cuando el número de extranjeros llegaba al 50\% de la población. Entre aquellos, la primera mayoría estaba conformada por italianos, es decir, no hispanohablantes, lo que ha llevado a un desarrollo sin precedentes en las políticas lingüísticas estatales volcadas al fortalecimiento del Idioma Nacional (DI TULLIO, 2010; PÉREZ y ROGIERI, 2013). La segunda hipótesis se relaciona con la política lingüística universitaria desarrollada a fines del año 2017: la necesidad de certificar el conocimiento lingüístico podría funcionar como estímulo para el aprendizaje del idioma.

\section{MATERIALES Y MÉTODOS}

Este es un estudio exploratorio de carácter cualitativo que se erige sobre una base interdisciplinaria, movilizando conceptos del psicoanálisis, de la lingüística aplicada y de la educación. Concebimos el sujeto como ser humano constituido en una lengua (BENVENISTE, 1966/2015) e interpelado por otras (CORACINI, 2007; DERRIDA，1996/2012; REVUZ，1992). En esta intersección, la corriente teórica del Análisis del Discurso (AD) de origen francés (AUTHIER-REVUZ, 2004; PÊCHEUX, 1975/2016) y brasileño (ORLANDI, 2015, 2011) aporta una base fundamental.

El corpus del estudio comprendió los textos de las siguientes fuentes: 1) Documentos institucionales: Ordenanza N 728 (2017) del Consejo Superior de la UNR y Boletines Estadísticos ${ }^{4}$ de la universidad (de números 64 y 69 referentes a los años de 2012 y 2017); 2) Noticias periodísticas en línea referentes a la presencia de estudiantes de Medicina brasileños instalados en Rosario (período 2017-2018); y 3) Entrevistas semiestructuradas transcriptas realizadas a seis sujetos: un informante clave de la UNR, tres estudiantes de segundo año oriundos de Brasil, uno de primer año y un médico brasileño graduado en el 2018. El perfil de este último informante fue particularmente importante porque contempló la experiencia de cursado antes

4. Los Boletines Estadísticos de la UNR tienen como objetivo brindar información cuantitativa respecto a estudiantes y egresados de las carreras de pregrado, grado y posgrado en determinado año académico. Los mismos son elaborados por la Dirección General de Estadística Universitaria que depende de la Secretaría de Planeamiento de la Universidad. Las Facultades cuentan con bases de datos informatizadas en sus secciones de alumnado para proveer la información que alimenta a los boletines. 
y durante el fenómeno del arribo masivo de brasileños. El corpus de análisis fue construido a partir de la selección de secuencias discursivas (SD) pertinentes a los objetivos del estudio, en función de las regularidades discursivas relacionadas a los temas de interés. Es importante mencionar que cualquier discurso siempre se establece en relación a un discurso previo y se proyecta a otro. Por tal motivo, lo que existe son procesos discursivos de los cuales se puede recortar y analizar diferentes estados (ORLANDI, 2015).

La guía para las entrevistas a los brasileños -realizadas en portuguéscontempló las siguientes cuestiones: autopercepciones sobre el manejo de la lengua española desde la llegada a Argentina; observaciones sobre la presencia de brasileños en la facultad; apropiación de la jerga médica en otro idioma y repercusiones de la nueva política universitaria. Con respecto al informante clave de la universidad, la entrevista fue realizada en español y versó sobre la nueva política lingüística. La investigación ha seguido el protocolo ético institucional que consiste en que los participantes firmen un consentimiento informado.

Finalmente, nos guiamos por algunas preguntas orientadoras: ¿̇or qué el número de estudiantes de medicina brasileños aumenta exponencialmente en Rosario?, ¿Cómo lidian ellos con la nueva lengua y cultura?, ¿Cuáles son las circunstancias que sostienen sus intercambios lingüísticos?, ¿De qué forma autoperciben su modo de hablar en el territorio de inmersión?, ¿En qué medida los aspirantes se sienten afectados por la exigencia del nivel B2 del idioma español? Desde el punto de vista lingüístico, ¿̇e qué modo el actual aluvión de brasileños afecta la estadía del estudiante extranjero en la comunidad de destino?

Estos ejes funcionaron como disparadores para que los participantes bablaran. De ese modo, las investigadoras tuvieron la tarea de invitar a los sujetos participantes a que hablaran de sí a partir de los tópicos predefinidos. Desde el campo discursivo aquí abordado, se entiende que el sujeto está atravesado por el inconsciente y por la ideología. De ese modo, lo que se dice significa más allá de lo dicho. Según Orlandi (2015), los sentidos no están en las palabras en sí, sino antes y más allá de las mismas. En esta línea, la sintaxis significa. Además, se entiende que la paráfrasis opera a nivel de aquello que se mantiene en el discurso, mientras las operaciones polisémicas denotan deslices o rupturas en los procesos de significación. De ese modo, es en esta tensión entre lo mismo y lo diferente que los discursos producen sentidos.

Nuestro dispositivo de análisis se basó, entonces, en el corpus de análisis, en nuestro marco teórico y en la literatura respecto al tema general del estudio (estudiantes migrantes e interligüística). Así, buscamos relacionar los sentidos 
encontrados con lo histórico-ideológico constitutivo de cada discurso, aportando gestos de interpretación no solo respecto al nivel intradiscursivo (la materialidad lingüística), sino también respecto al nivel interdiscursivo (la memoria discursiva que autoriza lo que puede y debe ser dicho en las circunstancias presentadas).

Como plantea Orlandi (2015), se trata de establecer una escucha discursiva que acoja la opacidad del lenguaje. Por lo tanto, se coincide con el supuesto de que el lenguaje no es transparente y que siempre imprime un espesor semántico. Así, es menester comprender el eje acotado -las secuencias discursivas- como una unidad discursiva en relación a un todo, que nos permite interpretar el fragmento en vistas a llegar a una comprensión.

\section{RESULTADOS Y DISCUSIÓN}

A partir de los objetivos específicos del estudio, en esta sección, presentamos los resultados y las discusiones obtenidos a través de nuestro dispositivo de análisis a la luz de otros estudios relacionados al tema. Empezamos presentando datos del contexto inmediato de producción de los discursos analizados.

De los Boletines Estadísticos $N^{0} 64$ y 69 se desprende que en el año 2012 la primera mayoría de estudiantes en la UNR oriundos de América del Sur correspondía a peruanos. En este entonces, se registraba 311 estudiantes brasileños entre inscriptos y nuevos inscriptos. En cinco años, este número octuplicó, pasando a ser de 2577 brasileños en el 2017, como se observa en la Figura 1:

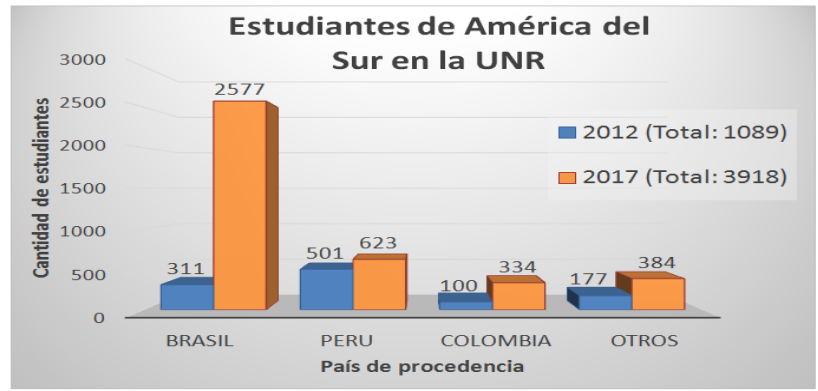

Figura 1. Total de estudiantes oriundos de países de América del Sur en la UNR en los años 2012 y 2017.

Fuente: elaboración propia. 
En el año 2017, del total de 3.918 estudiantes extranjeros oriundos de América del Sur -entre inscritos y nuevos inscritos-, 2.577 eran brasileños (65\%), de los cuales 2492 se concentraban en el Área Salud, como se puede visualizar en la Figura 2.

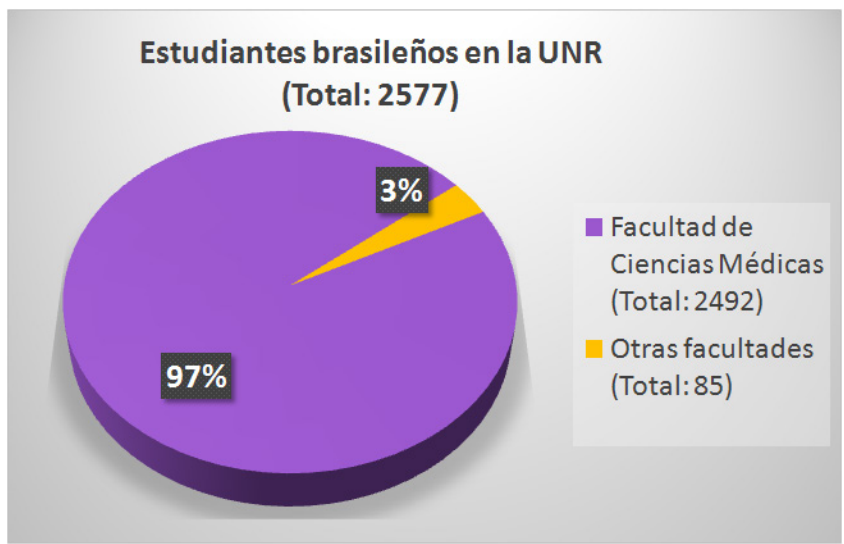

Figura 2. Distribución de los estudiantes brasileños (inscriptos y nuevos inscriptos) en las Facultades de la UNR.

Fuente: elaboración propia.

Aún en el año 2017, el número total de nuevos inscritos extranjeros en la universidad se había contabilizado en 572, entre los cuales 547 correspondían a matriculados en la carrera de Medicina. Entre estos, 472 eran provenientes de Brasil. Estos números deben ser considerados como aproximados, pues, en los boletines estadísticos, existen estudiantes cuyo lugar de procedencia no está determinado. Asimismo, se estima que la cifra de nuevos inscriptos brasileños en Medicina en el año 2018 circundó los 1300 (LA CAPITAL, 2018).

A esto sumamos que, según nota realizada por el periódico El Mirador Provincial al entonces Decano de la Facultad de Ciencias Médicas, Ricardo Nidd, los brasileños representan diez por ciento del total de estudiantes de la Facultad (ÁLVAREZ, 2018). Estos datos confirman la tendencia actual de un boom de estudiantes de Medicina en Rosario provenientes de Brasil.

En este sentido, Frigerio (2005) advirtió que los brasileños instalados en Buenos Aires a principios del nuevo milenio eran tratados más positivamente que otros extranjeros latinoamericanos. Sin embargo, la autora alerta que un incremento en la presencia de brasileños podría cambiar el perfil de valoración positiva. En lo que atañe a nuestro estudio, el brasileño estudiante de Medicina podría ser visto negativamente por los locales por ocupar el lugar de un argentino en la universidad 
nacional. De hecho, ese tipo de apreciación se ha popularizado en el discurso social. Luchilo (2018) advierte que:

En una emisión del programa Periodismo para todos ${ }^{5}$ de octubre pasado [2017] se afirmó que en la Universidad de Buenos Aires estudian casi 13.000 estudiantes extranjeros y que estos estudiantes representan un costo de unos 360 millones de pesos. El supuesto detrás de esta afirmación es que las universidades públicas argentinas, sostenidas por los impuestos que pagamos los que vivimos en el país, estarían subsidiando a estudiantes provenientes de otros países y que ese subsidio no sería justificado. (SD1)

La nota explica que entre estos casi 13.000 estudiantes extranjeros, hay muchos que se instalan para vivir permanentemente en el país. A su vez, hay otros que no son migrantes de primera generación, ya que tienen familiares directos argentinos. En ambos casos, los estudiantes también serían partícipes del pago de impuestos. Esto apunta a que el programa televisivo hace uso de cifras infladas para argumentar en favor de la instalación de una verdad evidente (PÊCHEUX, 2016) que podría ser enunciada del siguiente modo: "como si los problemas económicos de la Argentina fueran pocos, encima subsidia a estudiantes extranjeros". A nivel intradiscursivo, equiparar estudiantes extranjeros a costo funciona para agudizar la crítica negativa a la absorción de extranjeros en la enseñanza superior pública argentina. Desde este razonamiento, se pone al descubierto los sentidos no evidentes del discurso incitado por el programa de televisión y que se escucha en las voces de ciudadanos comprometidos con una ideología liberal. En el contexto microregional, estos tipos de resonancias discursivas han llevado el entonces Decano de la Facultad de Ciencias Médicas de la UNR a esclarecer la situación. El mismo declaró que el brasileño que vive en Rosario (así como otros extranjeros) gasta en bienes y servicios un monto suficiente para dejar en el país impuestos de suma equivalente a lo que vale, para el gobierno, un cupo en la universidad pública. Así lo expresa (ÁLVAREZ, 2018):

Hay un mito que dice que los brasileños vienen acá, estudian y se llevan el esfuerzo de los argentinos. Es una mentira. ¿Cuánto le cuesta al Estado nacional un estudiante en la Universidad Nacional de Rosario? Más o menos 5.000 pesos por mes. Un brasileño, un peruano que trae el dinero de afuera, que si no viene a estudiar no lo trae, si gasta el doble de esos 5.000 pesos, ya le dejó al fisco los 5.000 pesos para pagar sus estudios y gasta mucho más que el doble. Con 10.000 pesos no vive. Tiene que pagar alquiler, impuestos, gastos centrales, consumo, salidas, transporte, material de estudio. (SD2)

5. Se trata de un programa argentino de alcance nacional transmitido los domingos por el canal El Trece TV, vinculado al Grupo Clarín. 
Como señala Orlandi (2007), lo no dicho carga toda la posibilidad del decir y significa tanto como lo que se dice efectivamente. En la SD2, ese no dicho se representa por el mito evocado. Allí, el espacio silenciado tiene tanta fuerza como el discurso que lo invoca por la ausencia. Se confirma la existencia de un mito que supone que los brasileños les roban algo a los argentinos, ya que los primeros "vienen, estudian y se van". Esta representación nacional de estar siendo estafado por otro país evoca memorias relacionadas al enojo como, por ejemplo, la relación entre Argentina, Estados Unidos y el Fondo Monetario Internacional. Entre los enunciados posibles, elegimos identificar aquellas regularidades discursivas más cercanas a nuestro objeto de estudio. Así, rescatamos la presencia de dos sentidos respecto al estudiante brasileño: por un lado, que es un costo más para el pueblo argentino y, por el otro, que su propio país no se hace cargo de su formación.

Con respecto a la importancia del corpus periodístico, Di Tullio (2010, p. 18) afirma que "el discurso del prejuicio se construye y se difunde prioritariamente a través de los medios de comunicación masiva.". Siguiendo esta lógica de construcción de prejuicios, presentamos finalmente uno de los titulares que pone de relieve una caricatura negativa de la llegada de los brasileños: Invasión de brasileños en la Facultad de Medicina de Rosario (RADIO EME, 2018). Un vez más, la elección lexical del sustantivo invasión contribuye para generar efectos de sentidos negativos respecto a la llegada de brasileños. Apelando a su espesor semántico, la palabra invasión evoca la guerra, la disputa, la intromisión de cuerpos extraños o extranjeros. Remite a lo ajeno que invade la intimidad, la zona de confort. Ahora bien, recurriendo a una sustitución paradigmática podríamos tener, por oposición a estos sentidos, el siguiente titular: "Llegada de brasileños a la Facultad de Medicina de Rosario". Cuándo se propone esta alternativa enunciativa -a partir de lo que podría haber sido dicho pero no lo fue- se afianza el gesto de interpretación respecto a la manifestación de discursos xenófobos.

Antes de continuar con el análisis, remetimos a otros aportes que también componen el escenario de nuestros interrogantes. En este sentido, Klett (2017) discute la noción de internacionalización de la educación superior y advierte, en los textos académicos del área, una expectativa declarada de potencializar la interculturalidad. Pese a esto, la autora señala que el acento en la concepción de reciprocidad desplegado del término inter no se ve reflejado en los textos institucionales que buscan regular dicha internacionalización. Se observa, más bien, un direccionamiento rumbo a la adaptación del Otro a la cultura local. En palabras de la autora: "el espíritu que predomina en el texto sería aquel de la inserción de lo que viene de afuera, sobre todo desde el punto de vista cultural, con un país 
activo y un otro receptivo6." (KLETT, 2017, p. 59, nuestra traducción). Esto es exactamente lo que constata Da Rosa (2018) cuando analiza los discursos oficiales sobre el acogimiento/inserción de refugiados en universidades públicas brasileñas, representando la problemática en la impar dicotomía inicialmente planteada por Derrida (2000): hospitalidad versus hostipalidad, neologismo empleado para destacar la hostilidad revestida de hospitalidad.

Sumándose a estas posiciones, García Canclini (2004) aborda el concepto de interculturalidad desde una perspectiva compleja que absorbe tanto el encuentro como la confrontación entre culturas y, se podría agregar, entre lenguas. De ese modo, se asume la heterogeneidad y las contradicciones constitutivas de cualquier sociabilidad humana. Finalmente, también se toma en cuenta el concepto de interculturalidad previsto desde una perspectiva decolonial. En este sentido, Walsh (2010) subraya el prefijo inter del concepto: en una relación auténticamente intercultural, no se prioriza un grupo social que se dispone a incluir a otro, sino que se alienta a un intercambio real, en el que se espera que las dos comunidades afectadas puedan no solo influenciarse mutuamente, sino también reconocer recíprocamente la intención de relacionarse en doble mano.

A continuación, presentamos el análisis a partir de los tres ejes planteados al principio del artículo.

\subsection{La nueva política lingüística universitaria: exigencia del nivel B2}

La Ordenanza $n^{\circ} 728$ (UNR, 2017), que entre otros aspectos versa sobre la exigencia de que aspirantes no hispanohablantes acrediten conocimiento de la lengua española con nivel B2 o superior, parte de las siguientes premisas: a) la dificultad en la comprensión y expresión lingüística que hace que "el espacio académico se convierta indirectamente en el ámbito de aprendizaje de la lengua" (p. 1), b) la Resolución de Consejo Superior $n^{0} 722$ (2017) que dispone sobre la acreditación del nivel B2 de conocimiento de la lengua española a aspirantes no hispanohablantes a carreras de posgrado, c) la dinámica similar adoptada por otras universidades argentinas, d) la adopción de estas medidas en algunas Unidades Académicas de la UNR (como la Facultad de Odontología), e) la integración de la UNR al Sistema Internacional de Certificación del Español como Lengua Extranjera (SICELE) desde el 2007, f) la Resolución no 724 (2005) que aprueba, en la UNR, la creación del Diploma Universitario de Competencia en Lengua Española como

6. En original: "l'esprit qui prédomine dans le texte serait plutôt celui de l'insertion de ce qui vient d'ailleurs surtout du point de vue culturel, avec un pays actif et un autre réceptif." 
Lengua Extranjera (DUCLE), con parámetros internacionales, g) las modificaciones en la legislación educativa a nivel nacional respecto al tema y h) los aportes de las Comisiones de Asuntos Académicos y de Interpretación y Reglamentos, y la Asesoría Jurídica de la universidad. A partir de dichas consideraciones, se modifica el artículo 8 del Anexo I de la Ordenanza no 490 (UNR, 1989) que establecía, sin grandes precisiones, la aprobación de la asignatura Castellano como requisito para la inscripción de aspirantes no hispanohablantes. Se ha modificado el texto con la incorporación de la obligatoriedad de acreditación de Nivel B2 (Intermedio Independiente) en lengua española para nuevos inscriptos no hispanohablantes a partir del año 2018, en todas las facultades de la universidad. Tal competencia puede ser certificada por el DUCLE u otros exámenes reconocidos por el SICELE, como el Certificado de Español Lengua y Uso (CELU), el Diploma de Español como Lengua Extranjera (DELE) o el Servicio Internacional de Evaluación de la Lengua Española (SIELE), este último realizado completamente en línea.

Esta presentación de la Ordenanza resulta relevante para contextualizar los próximos análisis. Tenemos en cuenta que el marco teórico-metodológico empleado habilita a comprender los enunciados singulares formulados por cada informante empírico desde sus posiciones como sujetos del discurso y sujetos al discurso.

La mayoría de los estudiantes brasileños que llega a Rosario no ha estudiado español antes del viaje. Advertimos que los recién llegados no tienen necesidad inmediata de hablar castellano, ya que se manejan entre los miembros de la comunidad de brasileños, término utilizado por ellos. Además, las primeras clases de la carrera de Medicina son expositivas, por lo que son expuestos, sobre todo, a la competencia auditiva. La demanda por expresión oral llega en el segundo cuatrimestre, con los primeros exámenes finales ${ }^{7}$. De ese modo, la exigencia de certificación podría funcionar como estímulo para la búsqueda de un aprendizaje previo a estas instancias.

A ese propósito, un ingresante 2018 confiesa que llegó al país "com a cabeça já no B2, nem cheguei com a cabeça na faculdade, cheguei, tipo, preciso passar no B2, preciso passar no B2. ${ }^{{ }^{8 \prime}}$ (SD3). Se destaca a nivel intradiscursivo la repetición del último sintagma verbal. Este recurso lingüístico acentúa y dramatiza la preocupación del estudiante con la cuestión idiomática, que devino a partir de la exigencia del certificado. A

7. En Argentina, la evaluación de los estudiantes universitarios en el interior de las cátedras universitarias suele ocurrir por medio de los llamados exámenes finales que, comúnmente, comparten las siguientes características: son de carácter individual, modalidad oral, constituidos por un tribunal de por lo menos tres docentes del área, y recorren diferentes temas del programa de la cátedra.

8. A lo largo del texto, optamos por mantener en idioma original las secuencias discursivas seleccionadas. En las notas al pie, presentaremos las traducciones, siempre de nuestra responsabilidad. En este caso: "con la cabeza en el B2, ni llegué con la cabeza en la facultad, llegué, tipo, necesito aprobar el B2, necesito aprobar el B2". 
nivel paradigmático, se observa un deslizamiento semántico entre acreditar el nivel intermedio en lengua española y el significante B2. Agudizando el análisis, se establece una relación de sustitución dónde lengua española equivale a B2. Esta sustitución produce un efecto de verdad que encubre la complejidad implicada en la adquisición de una nueva lengua. Passar no $\mathrm{B}_{2}$ implica aprobar un examen, eximiendo el estudiante de los complejos movimientos subjetivos que podría atravesar en los procesos de adquisición de una lengua extranjera. Se pone en evidencia una contradicción. Por un lado, el peso de encontrarse con una nueva lengua-cultura se aliviana con el procedimiento de sustitución de la idea de aprehender una nueva lengua por la idea de aprobar el B2. Por el otro, el estudiante experimenta suficiente euforia, preocupación y miedo con el deber de aprobar el B2, lo que queda más explícito en la siguiente SD:

Cheguei em janeiro [de 2018], fiz exame em abril, e já aprovei no exame de abril... Por medo, eu acabei pagando o exame de abril [risos] e o exame de maio, porque en fiquei com medo de não passar no exame de abril... Fiquei com medo porque demora o resultado né..., aí eu acabei pagando, fazendo as duas, e acabei passando na primeira [risos], e passei na segunda também? (SD4)

Lo que se espera para el nivel B2 de un idioma responde a, por lo menos, dos años de estudio, hecho que, en el caso invocado, se logró con tres meses de preparo. Aunque haya sorteado doblemente la nueva exigencia, el mismo estudiante sostiene que su amigo ingresante del año previo -2017-, no tuvo que certificar su dominio del español y, sin embargo, habla mejor que él.

En la SD4 queda en evidencia la repetición de algunas palabras. Si bien el significante medo se repite tres veces, se advierte que exame se repite cinco veces. Este último significante, si bien existe en el léxico portugués, es menos frecuente, ya que en su lugar se suele utilizar el significante prova. A su vez, en castellano, sobre todo en el ámbito universitario, la palabra examen es repetida cotidianamente. Aclaramos esto porque se advierte un equívoco producido en la SD4 que, por su presencia, da cuenta de lo que falta o a qué remite. Al final de la secuencia, en medio a risas, el estudiante afirma que pagó y rindió as duas, y terminó passando na primeira $e$ na segunda. El uso del género femenino en los artículos, preposiciones y adjetivos utilizados no registra ningún antecedente en el texto. Solo lo podemos reponer a partir de evocar la memoria discursiva de un estudiante brasileño que remite, por lo tanto, a las provas para certificar el nivel B2. De ese modo, las apariciones concretas

9. "Llegué en enero [del 2018], hice el examen en abril, y aprobé el examen de abril... Por miedo, terminé pagando el examen de abril [risas] y el examen de mayo, porque yo tuve miedo de no aprobar el examen de abril... Tuve miedo porque tarda el resultado viste..., entonces terminé pagando, haciendo las dos, y terminé aprobando la primera [risas], y aprobé la segunda también." 
de la palabra exame sumadas a los complementos del significante prova impregnan la SD4 del sentido -y sentimiento- de aprobación que el estudiante busca una y otra vez, en pos de ser acepto en la universidad o integrado a la comunidad de destino.

Asimismo, el estudiante continúa el hilo de su discurso sosteniendo que algunas personas tienen más facilidad para aprender un idioma, mientras otras requieren más esfuerzo, lo que califica como siendo su caso. Afirma que estar en contacto con la lengua ayuda mucho. Así continúa su relato:

[o contato com o espanbol] é mais na faculdade, mais na faculdade... Eu moro com três brasileiras, todo o tempo português, eu falo até que essa questão do paro agora atrapalhou um pouquinho o aperfeiçoamento do men espanbol, porque você fica o tempo inteiro dentro de casa, né, e você não tem muito contato com a língua ${ }^{10}$. (SD5)

Se advierte que la facultad se sostiene como principal reducto donde se utiliza el español. Se pone de relieve que el estudiante y las estudiantes habitan dos mundos, auténticos sujetos entre lenguas: uno íntimo, simbolizado por un lugar privado -su casa-, en donde se habla su lengua materna y se cultiva en alguna medida sus raíces; otro foráneo, simbolizado por un lugar público e institucionalizado -la facultad-, en la que la lengua mayoritaria es otra, extraña, ajena, extranjera. Kristeva (1994) se remite a esta experiencia cuando fundamenta el concepto de inquietante extranjería, que congrega una comunión solidaria de opuestos, tal como sostiene Freud (1919/1997) cuando aborda lo ominoso, con el par beimlich-unbeimlich ${ }^{11}$. En este punto, cabe mencionar que en nuestras investigaciones venimos formulando la noción de lengua-bogar, como la lengua en la que el sujeto se siente acogido (que puede ser su primera lengua u otra), y lengua-lugar, en la que tiene que hacerse cargo de su lugar de sujeto social más allá de sus deseos más íntimos (ANGELUCCI, 2017).

Recuperando otros sentidos de la SD5, se advierte que el paro mencionado se refiere al periodo de huelga de los docentes universitarios argentinos entre los meses de setiembre y octubre del 2018. Se trata de una interferencia interlingüística que se podría traducir al portugués como greve, o bien paralisação. Es importante contextualizar que la dinámica de paros suele afectar a los distintos niveles del sistema educacional argentino, con una frecuencia sostenida a lo largo del año académico, especialmente en la época de las paritarias docentes. Si bien, como se

10. "[el contacto con el español] es más en la facultad, más en la facultad... Yo vivo con tres brasileñas, todo el tiempo portugués, yo incluso digo que esta cuestión del paro ahora jodió un poquito el perfeccionamiento de mi español, porque vos te quedás todo el tiempo dentro de casa, ćno es cierto?, y vos no tenés mucho contacto con la lengua."

11. Groseramente, se puede traducir beimlich por secreto, y unbeimlich por ominoso/terrorífico. La idea que se transmite es de lo íntimo y de lo extraño que mutuamente se enfrentan y se solidarizan "intercambiando roles". 
anunció, existen palabras para identificar esta situación en portugués, la experiencia vivida con mayor frecuencia en el país de inmersión aporta espesura suficiente al significante paro que lo hace ser incorporado a la lengua de los brasileños que estudian en Argentina. Dicho esto, según el informante, el paro "molestó" su español. El paro toma entidad de sujeto, a que se le atribuye una acción. Haber quedado más de un mes sin clases se transforma en sinónimo de haber quedado durante igual período sin hablar español. En el nivel intradiscursivo, es oportuno observar cómo el sujeto se despoja de su responsabilidad enunciativa: "no fui yo quien aflojé, sino un agente externo quien me perjudicó".

Según se ha anticipado, Da Rosa (2018) estudió la formulación del discurso sobre los refugiados en los documentos institucionales brasileños que reglamentan su admisión en las universidades públicas de este país y el funcionamiento del discurso institucional en las políticas de integración de los extranjeros. Con respecto al componente lingüístico, la autora constata que "la exigencia de inserción del refugiado en la lengua portuguesa por intermedio de un examen que mide su competencia posee un efecto limitador ${ }^{12 .}$." (DA ROSA, 2018, p. 1545, nuestra traducción). En el caso de Rosario, instaurar un examen de lengua como condición de permanencia del estudiante brasileño evidentemente limita el acceso otrora irrestricto. Sin embargo, ¿Cómo garantizar la intercomprensión entre los miembros de la comunidad académica y, por consecuencia, la permanencia y continuidad de esta población en la universidad?

Ante lo dicho, se observa que la aprobación del examen de lengua todavía no viene garantizando una expresión oral fluida. Una docente de la UNR, en ponencia realizada en la marco del Congreso Internacional del SICELE (RODRÍGUEZ, 2018), expuso su experiencia de enseñanza de español a una cohorte de no hispanohablantes en el primer año de la carrera de Medicina (materia optativa dictada en el primer cuatrimestre del 2018). La docente sostuvo que han llegado a sus cursos estudiantes brasileños que ya habían adquirido la certificación de nivel B2, pero sentían necesidad de mejorar su español. Respecto al hecho, la docente lo relaciona precisamente con la acomodación de los estudiantes y de los cursos preparatorios al modelo de los exámenes. En otros palabras, la aprobación es satisfactoria en tanto los aspirantes cumplen con los requisitos esperados; no obstante, no están por eso preparados para posicionarse como sujetos de la nueva lengua. A partir de estos datos, se puede inferir que la certificación no viene garantizando lo que se espera para un nivel intermedio avanzado (según lo que

12. En original: "a exigência de inserção do refugiado na lingua portuguesa por meio de um exame que afere sua proficiência possui um efeito limitador". 
prescribe el Marco Común: comprensión de textos complejos, relación fluida con hablantes nativos y producción de textos claros).

Estos resultados coinciden con un estudio enmarcado en el campo de la internacionalización de la educación superior, realizado en la Facultad de Medicina de la Universidad Abierta Interamericana (UAI) de Rosario, donde también ha aumentado sustancialmente el número de matriculados brasileños (AGOSTINI, GABINI, FERNÁNDEZ, PACHECO y WEISBURD, 2017). La migración de estudiantes brasileños para estudiar Medicina en la Argentina abarca no solo el medio universitario público, sino también el privado.

En la Facultad de Medicina de la UAI, existen tres tipos de estrategias de internacionalización: las previas al ingreso, las que se desarrollan durante el cursado y las posteriores al mismo. Entre las estrategias previas al ingreso se encuentran: curso de comunicación oral y escrita en español, cursillo de introducción (biología y fisicoquímica), Open Day (la universidad abre sus puertas a la comunidad con ofrecimiento de talleres, charlas, orientación vocacional, entre otros), becas para extranjeros, programas de movilidad académica y, lo que más nos interesa, curso de idioma para no hispanohablantes (extracurricular). Por su parte, las estrategias durante el cursado contemplan proyectos de socialización (actividades lúdicas, charlas y otras prácticas de habilidades sociales que faciliten la vida universitaria), tutorías, investigación, extensión, portafolio electrónico y conexión (programa de radio En línea la salud). Finalmente, la estrategia posterior al cursado responde a la posibilidad de realizar la Reválida del título en el país de origen de los egresados. El estudio concluye que las actividades de extensión fueron las más convocantes entre los estudiantes extranjeros en el periodo. En el otro extremo, la participación en los cursos de español como lengua extranjera (ELE) fue muy baja. Asimismo, aunque el departamento pedagógico de la universidad prevé un examen de idioma, "el mismo no resulta totalmente idóneo para evaluar sus capacidades [de los estudiantes no hispanohablantes] en este aspecto." (AGOSTINI et al, 2017, p. 39). El estudio apunta, en síntesis, que el examen de lengua implementado en dicha universidad tampoco ha garantizado, todavía, la resolución del conflicto lingüístico.

Con respecto a lo que fue analizado y discutido en este apartado, a partir de las entrevistas, agregamos que algunos estudiantes tienen dificultades para expresarse oralmente al momento de solicitar sus acreditaciones de nivel B2 en la oficina del PRAELE, situada en la Facultad de Humanidades y Artes de la UNR. El hecho refuerza la duda respecto al examen de lengua como garantía de dominio del idioma y consecuente adaptación a los estudios específicos. 
Corresponde mencionar, aún, que la mayoría de los inscriptos en los cursos preparatorios de ELE ofrecidos por la UNR durante el año 2018 no provenía de Brasil, sino de Haití. Pese a la falta de estadísticas oficiales, se estima que hubo más del $50 \%$ de desaprobación. Ahora bien, si no se inscriben en los cursos ofertados por la universidad, cdónde, entonces, se preparan los brasileños para rendir? Existen institutos de idiomas privados habilitados para realizar exámenes como el DELE, certificado por el Instituto Cervantes, de España, que goza de mayor prestigio en el público meta. Volveremos a esta cuestión en las consideraciones finales de este trabajo.

\subsection{El fortalecimiento de la comunidad lingüística brasileña}

Estudios fundamentados en la Psicología resultan relevantes para pensar la situación. A partir de entrevistas realizadas con estudiantes universitarios extranjeros instalados en Argentina, Castro Solano (2011) y su equipo abordaron las estrategias aculturativas (adaptación psicológica, sociocultural, académica, satisfacción vital y discriminación percibida) empleadas por la referida población. En dicha investigación, se emplearon las categorías de integración (el migrante intenta mantener su herencia cultural y también entablar contacto con el grupo dominante), asimilación (el migrante no conserva su cultura de origen e intenta mantener contacto solamente con miembros del grupo dominante), marginación (el migrante no tiene interés o posibilidad tanto de mantener su cultura materna, como de entrar en contacto con la cultura receptora) y separación (el migrante consigue mantener su cultura original, pero evita la interacción con otros grupos). La marginación fue la estrategia menos utilizada entre los participantes, mientras que la integración fue la preferida, con resultados adaptativos relacionados a la mayor satisfacción con la vida académica y en general. La cuestión lingüística, no abordada por los autores, agrega complejidad a la situación.

Los informantes brasileños de nuestro estudio fueron unánimes en considerar que la mayoría de sus compatriotas se relaciona más con brasileños que con argentinos: en la convivencia doméstica, en actividades de esparcimiento, en la producción y consumo de alimentos típicos, en los grupos de estudios, entre otros. Con esto, se desprende que estos estudiantes tienden a emplear la estrategia de separación, hecho que difiere de las conclusiones del estudio previamente mencionado.

Podríamos afirmar que el fortalecimiento de una comunidad lingüística funciona como sostén emocional; con todo, afecta negativamente la apropiación de la lengua meta. Al respecto, el informante recién graduado comenta que hace 
seis años no era necesario exigir un examen de lengua en la universidad, ya que los estudiantes brasileños recién llegados, siendo muy pocos, eran obligados por el contexto sociocultural a aprender español. Según este informante, hoy en día, "o pessoal não tem dificuldade pra falar"13" (SD6), no porque estén familiarizados con la lengua meta -como se podría esperar desde una lectura basada en la superficialidad lingüística de la SD6-, sino porque o bien se hacen comprender apoyándose en la proximidad lingüística aparente, o bien esquivan la exposición al castellano manteniéndose prioritariamente en un entorno lusoparlante. Con relación a la primera opción, es menester recuperar la vigencia de la metonimia "español - lengua parecida - lengua fácil - lengua espontánea $=$ portuñol" (CELADA, 2002, p. 101) cuando el brasileño transita sus primeros pasos en el territorio de la lengua vecina.

Asimismo, Castro Solano y Lupano Perugini (2013) demostraron que cuando el estudiante establece buenos vínculos tanto con sus compatriotas, como con los locales, se produce una fuerte adaptación psicológica, traducida en mejor rendimiento académico, mayor satisfacción vital y menores índices de ansiedad. En lo que atañe al presente estudio, observamos dos situaciones extremas: unos estudiantes buscan desde el primer momento conectarse solo con los argentinos y su cultura, mientras que otros no hacen grandes amistades ni con argentinos, ni con compatriotas. A partir de las entrevistas, se interpreta que, en el primer caso, la apropiación lingüística es más efectiva, mientras que, en el segundo caso, se incurre a mayores dificultades. En el medio de estas antípodas está la situación mayoritaria: brasileños que se reúnen entre sí.

Una ingresante del año 2017 afirma que en la Facultad de Ciencias Médicas es raro que los brasileños tengan amigos argentinos. En su caso personal, afirma:

Quando en cheguei aqui, a primeira coisa que en fiz foi me distanciar de brasileiros, primeira coisa que en fiz. Fiz amizade com argentinos, muitos argentinos. [... é terrível o jeito que os brasileiros falam aqui, de verdade, porque não se esforçam, e pensam que eles [os argentinos] são obrigados a entender a gente, na faculdade deles, entendeu... ${ }^{14}$ (SD7)

La informante atribuye la resistencia de los brasileños en mixturarse con los nativos a la cantidad de brasileños en la Facultad: "tem muito brasileiro na faculdade! [...] tá no pátio, tá falando português, tá na aula, tem todos os seus amigos brasileiros, tá falando português... ${ }^{15 "}$

13. "La gente no tiene dificultad para hablar."

14. "Cuándo yo llegué acá, la primera cosa que hice fue distanciarme de brasileños, primera cosa que hice. Hice amistad con argentinos, muchos argentinos. [...] es terrible el modo como los brasileños hablan aquí, de verdad, porque no se esfuerzan, y piensan que ellos [los argentinos] son obligados a entender nosotros, en la facultad de ellos, entendés..."

15. "hay muchos brasileños en la facultad! [...] está en el patio, está hablando portugués, está en el aula, tenés todos tus amigos brasileños, está hablando portugués..." 
(SD8). En la primera parte de la SD7, se repiten tres veces el verbo hacer, que denota acción. Se podría interpretar que la estudiante ejerció una doble acción primordial y deliberada: distanciarse de brasileños y acercarse a argentinos. El verbo de acción de la primera parte de la secuencia resuena opuestamente con el reproche que hace a los otros compatriotas que não se esforçam. Con esto, la estudiante valora su acción en contraposición con la no acción de los demás, poniendo de relieve que la adaptación lingüístico-cultural se conquista con esfuerzos. En la SD8, vemos que se refuerza el vínculo antes evocado entre hablar bien y tener amigos argentinos, por un lado, y hablar terrible y tener solo amigos brasileños, por el otro. Sumándose a eso, la entrevistada da muestras de cómo el (des)encuentro interlingüístico se manifiesta en la cursada: no todos los profesores son tolerantes, habiendo casos en que los estudiantes brasileños son reprobados en los exámenes no por falta de conocimientos sobre el contenido de la materia, sino por su despliegue lingüístico desfasado. El acontecimiento estimula a investigar otras problemáticas, como el rol docente en las circunstancias interlingüísticas que vienen excediendo la capacidad institucional de responder con una planificación acorde.

Otro informante ingresante 2017 cuenta que fue ridiculizado en un negocio cuando apenas llegó a la ciudad. Lo cuestionaron sobre cómo iba a estudiar Medicina si ni siquiera sabía hablar. El evento le produjo un insigbt y funcionó como estímulo para el estudio de la nueva lengua. En esta línea, "La impericia lingüística se convierte en un objeto privilegiado de sátiras: la torpeza del inmigrante que no domina la lengua de la sociedad receptora se interpreta como síntoma de su inferioridad intelectual." (DI TULLIO, 2010, p. 33). De ese modo, apropiarse de la lengua ajena simboliza, también, recuperar poder y ponerse a la par.

Esta anécdota se relaciona con los datos obtenidos en la entrevista con la autoridad universitaria. Según la informante 5, la Secretaría de Español Lengua Extranjera de la UNR había sugerido adoptar el Nivel B1 como parámetro suficiente de conocimiento lingüístico, ya que los estudiantes estarían en situación de inmersión. Pese al argumento, el Consejo Superior optó por exigir el Nivel B2, nivel comúnmente exigido en las universidades de otros países. Efectivamente, el criterio de la inmersión, por sí mismo, operaba sobre la problemática cuando el número de no hispanohablantes en la universidad era bajo. El vertiginoso aumento de aquellos viene fortaleciendo su comunidad lingüística.

Respecto al contexto áulico, la Informante 2 afirma que:

Na tutoría, por exemplo, o tutor não é obrigado a entender português, acho que a gente que é obrigado a se esforçar e saber falar bem o espanbol [...] você vem pra um país bispanobablante, uma língua que é parecida com o português, você consegue se virar, agora se você vai pra um Estados Unidos da vida, que você tem que falar o inglês, você não 
tem como enrolar, ou você sabe ou você sabe. Não tem como você ir e começar a falar um portuinglês, sabe, igual o pessoal fala o portunbol aqui ${ }^{16}$. (SD9)

En esta secuencia, se evoca la memoria discursiva relacionada al inglés, admitido como lengua difícil, lengua cuya opción es saber o saber, y a los Estados Unidos como modelo de país en serio. Ese discurso ideológico termina de configurarse con su par opuesto: el portuñol admitido como lengua en la que se puede enrolar, se virar, dar um jeitinho $0^{17}$, y la representación de Brasil y Argentina cómo países subdesarrollados dónde todo se puede, dónde se permiten las trampas. Ahora bien, estas caras y contracaras se evidencian en la SD9 a modo de contradicción con otros supuestos que conviven en el mismo hilo del discurso, haciendo ver que las heterogeneidades sociales y discursivas se reflejan constitutivamente. Si bien la informante asume el discurso ideológico antes mencionado, al mismo tiempo, demanda a los brasileños que hablen bien, ya que están en un país hispanohablante que -condensado en la figura del tutor- no es obligado a entender la lengua portuguesa y que, además, debe ser respetado tal como se respeta a los Estados Unidos y al inglés.

Concluimos el apartado con el optimismo de uno de los entrevistados. Este señala que en su grupo de tutoría (materia de primer año), los tres estudiantes que fueron a coloquio, es decir, que tuvieron mejor desempeño académico durante el año, eran justamente brasileños. Esto muestra que las dificultades interlingüísticas enfrentadas por estudiantes y profesores de la FCM pueden ser y están siendo subsanadas.

\subsection{Las especificidades de la jerga médica}

No observamos dificultades relevantes respecto a la apropiación de la jerga médica. La base latina común entre el español y el portugués, sumada a la búsqueda de estabilidad que caracteriza a los tecnolectos determina más similitudes que diferencias con respecto a la terminología empleada en Brasil. La diferencia en la pronunciación fue lo que se apuntó como más dificultoso. Remarcamos que los exámenes finales en la Facultad de Ciencias Médicas son orales, o de múltiple elección, por lo que casi no se producen textos escritos. Así, la preocupación con

16. "En la tutoría, por ejemplo, el tutor no es obligado a comprender el portugués, creo que nosotros sí somos obligados a esforzarnos y saber hablar bien el español [...] vos venís a un país hispanohablante, una lengua que es parecida con el portugués, vos lográs manejarse, ahora si vos te vas a Estados Unidos ponele, donde tenés que hablar el inglés, vos no tenés cómo caretearla, o sabés o sabés. No se puede ir y empezar a hablar un portuinglés viste, igual la gente habla el portuñol aquí."

17. Son todos sinónimos para "buscarle la vuelta a algo". 
la expresión oral se sobrepone a la escrita. Prima el empeño en pronunciar bien determinadas palabras del vocabulario técnico.

Pese a lo dicho, es relevante profundizar el tema. Observamos que la pregunta formulada en las entrevistas respecto a la jerga médica se circunscribió al tecnolecto. No se pudo profundizar respecto al posicionamiento en un paradigma médico. A modo de ejemplo, ¿Cómo posicionarse en la diferencia epistémica que subyace al empleo del vocablo paciente o usuario de un servicio de salud sin conocer suficientemente un idioma? ¿Qué implicancias acarrea esta situación para la discusión crítica de los contenidos desarrollados en las materias? Estas son algunas de las cuestiones que ameritan futuras investigaciones.

\section{CONSIDERACIONES FINALES}

El terreno de los estudios sociolingüísticos en el campo de la internacionalización de la educación superior se presenta como sumamente fértil. En el caso de la UNR, la primera mayoría de extranjeros está actualmente conformada por brasileños, lo que conlleva a problemáticas lingüísticas tales como las abordadas en este estudio. Esa población se ha multiplicado de tal modo en los últimos años que llevó la Universidad a cambiar su política lingüística, buscando atender a la demanda de una intercomunicación más efectiva, además de obedecer a presiones políticas relacionadas al recorte de presupuestos. Con respecto a esto último, la obligatoriedad de la certificación en idioma español ha sido interpretada por algunos sectores como una restricción al acceso público a la enseñanza superior. A su vez, otros entienden que hablar el idioma del país en el cual se estudia es una cuestión elemental. El punto neurálgico es que acreditar un nivel de competencia lingüística no viene garantizando la resolución de los conflictos interlingüísticos. Una evaluación sobre la efectividad de la nueva política solo podrá realizarse a largo plazo; por el momento, enfrenta dificultades para proyectarse como herramienta autosuficiente.

Identificamos la oferta y enseñanza de ELE en este contexto como otra fuente prominente para estudios glotopolíticos. Entendemos que los cursos preparatorios de ELE para los exámenes de lengua se han transformado en fuentes de especulación financiera. La universidad tendría allí nuevas posibilidades de ingresos económicos, ya que ese tipo de cursos son pagos. Esto, sin embargo, no viene sucediendo. Aparentemente, los que están lucrando con la nueva obligatoriedad son algunos institutos de idiomas privados de la ciudad, que vienen ganando la competencia frente a los programas universitarios. 
Observamos que los brasileños tienden a desarrollar su vida social y académica entre pares de misma nacionalidad, lo que tiende a retardar su apropiación de la lengua de inmersión. Las dificultades de integración a la cultura meta se agudizan en el caso de los haitianos, cuya lengua oficial -el francés-, en su materialidad lingüística y discursiva, se distancia más del español que el portugués. Además de analizar tal cuestión, sería también interesante investigar comparativamente las problemáticas interlingüísticas entre las comunidades de nacionalidades hispanohablantes, como las de peruanos, colombianos o chilenos, agregando allí la veta de las variaciones lingüísticas.

La universidad pública argentina continúa convocada a ampliar las estrategias de inclusión social, sobre todo con estas nuevas problemáticas relacionadas a la llegada de migrantes y refugiados. Particularmente estos últimos se encuentran en alta a causa de las crisis actuales en países de la región, particularmente Chile, Bolivia y Venezuela. Tal cómo se plantea la importancia de la integración regional para fortalecer económicamente los países del cono sur frente al mundo, la universidad -que cumple un rol importante no solo en la producción y transformación de los conocimientos, sino también en la aplicación de estos a la realidad social concretamantiene el desafío de pensar y accionar rumbo a la integración universitaria, buscando potencializar la fortaleza que los intercambios interculturales representan. En este proyecto integracionista, que invoca a los tres poderes a nivel local y regional, hacemos especial referencia a la importancia de políticas lingüísticas basadas en una comprensión de la lengua amalgamada a la cultura.

Es difícil hablar de políticas universitarias sin pensar críticamente el propio rol que la universidad asume hoy en la sociedad latinoamericana. En este sentido, la perspectiva decolonial tiene mucho a aportar a las cuestiones interlingüísticas. Para Castro-Gómez (2007), por ejemplo, la universidad se inscribe en una estructura de colonialidad triangular, conformada por la colonialidad del ser, del poder y del saber. A partir de este diagnóstico, el autor propone un camino hacia la transculturalidad de saberes, dónde el trans remite a la condición de existencia de la tercera vía. Etimológicamente, trans tiene la misma raíz que tres, que implica trasgresión del dos. En este sentido, se estimula la superación de los pares binarios que han dominado el mundo moderno occidental y se asume, por lo tanto, la existencia de un tercer incluido. En esta línea, apuntamos a la importancia de los estudios relacionados al plurilingüismo y a la intercomprensión que van de la mano de la inclusión del tercero antes excluido. ¿Por qué hablar solo la lengua de origen? ¿Por qué hablar solamente la lengua de destino? Son preguntas con respuestas complejas pero que, 
justamente, desde el paradigma emergente del pensamiento complejo tienen mucho que aportar al campo de estudios sobre lenguaje y sociedad.

A modo de cierre, señalamos que la internacionalización de la educación superior acarrea, como condición sine qua non, preocupaciones interlingüísticas. Para seguir profundizando la problemática, la propia comprensión del rol de la universidad se hace imprescindible. En este estudio, hicimos nuestro aporte desde el análisis de un caso particular dónde quedan expuestas las perspectivas singulares y discursivas con las que actores sociales y políticos buscan manejar la situación de (des)encuentro lingüístico.

\section{REFERENCIAS}

AGOSTINI, M.; GABINI, S.; FERNÁNDEZ, F.; PACHECO, S.; WEISBURD G. (2017). Internacionalización de la educación en Medicina: el caso de la Universidad Abierta Interamericana, Sede Rosario. Revista da UIIPS. v. 5, nº 5, pp. 33-40. Disponible en: https://revistas.rcaap.pt/uiips/article/view/14542/10927. Acceso: 20 jul. 2018.

ÁLVAREZ, H. (2018). Continúa el fenómeno de los brasileños que llegan a Rosario para estudiar Medicina en la UNR. El Mirador. 12 mar. 2018. Disponible en: http://www. miradorprovincial.com/? $\mathrm{m}=$ interior\&id_um $=166575$-continua-el-fenomenode-los-brasilenos-que-llegan-a-rosario-para-estudiar-medicina-en-la-unr-pese-aalgunas-criticas-internas. Acceso: 20 abr. 2018.

ANGELUCCI, T. C. (2017). Secuencia Didáctica Lengua-lugar/Lengua-hogar: experiencia de intervención en el ámbito universitario desde géneros textuales líricos. En: $V$ Encuentro Internacional del Interaccionismo Sociodiscursivo: actividades de lenguaje, textos y discursos. Libro de Resúmenes. Rosario: Facultad de Humanidades y Artes-UNR.

ARANDA, L. (2018). El decano de Medicina ligó la discusión sobre extranjeros en la UNR a la falta de recursos. VíaRosario. 29 nov. 2018. Disponible en: https:/viapais.com.ar/ rosario/731430-el-decano-de-medicina-ligo-la-discusion-sobre-extranjeros-en-launr-a-la-falta-de-recursos/. Acceso: 5 mar. 2019.

ARNOUX, N. E. (2000). La Glotopolítica: transformaciones de un campo disciplinario. Primer simposio en la maestría en ciencia del lenguaje. Disponible en: https://www.academia. edu/24563971/La_Glotopolítica_transformaciones_de_un_campo_disciplinario. Acceso: 05 jun. 2018.

AUTHIER-REVUZ, J. (2004). Entre a transparência e a opacidade: um estudo enunciativo do sentido. Porto Alegre: Edipucrs. 
BARRANDEGUY, T. (2016). Cada vez más brasileños vienen a Rosario y deciden quedarse a vivir en la ciudad. La Capital. 15 may. 2016. Disponible en: https://www.lacapital. com.ar/la-ciudad/cada-vez-mas-brasilenos-vienen-rosario-y-deciden-quedarsevivir-la-ciudad-n790506.html. Acceso: 03 mar. 2018.

BENVENISTE, E. (1966/2015). Problemas de lingüística general I. México: Siglo Veintiuno Editores.

BUYSE, K.; POZZO, M. I. (2008). Léxico médico multilingüe para la enseñanza de lenguas y culturas con fines específicos. En: Actas del III Congreso Internacional Transformaciones culturales. Debates de la teoría, la crítica y la lingiuística. CD-ROM. Buenos Aires: Universidad de Buenos Aires.

CALVET, L. J. (2007). Sociolingüística: uma introdução crítica, trad. Marcos Marcionilo, $3^{\mathrm{a}}$ Ed. São Paulo: Parábola.

CARMO, M. (2018). Com faculdades públicas e sem vestibular, Argentina atrai cada vez mais universitários brasileiros. BBC Brasil. 16 abr. 2018. Disponible en: https://www. bbc.com/portuguese/brasil-43644403. Acceso: 20 mai. 2018.

CASTRO-GÓMEZ, S. (2007). Decolonizar la Universidad. La bybris del punto cero y el diálogo de saberes. En: Castro-Gómez, S.; Grosfoguel, R. (eds.), El giro decolonial. Reflexiones para una diversidad epistémica más allá del capitalismo global. Bogotá: Siglo del Hombre Editores, pp. 79-91.

CASTRO SOLANO, A. (2011). Estrategias de aculturación y adaptación psicológica y sociocultural de estudiantes extranjeros en la Argentina. Interdisciplinaria. v. 28, $\mathrm{n}^{\mathrm{o}} 1$, pp. 115-130.

CASTRO SOLANO, A.; LUPANO PERUGINI, M. L. (2013). Predictores de la adaptación sociocultural de estudiantes universitarios extranjeros en Argentina. Interdisciplinaria. v. $30, n^{\circ} 2$, pp. $265-281$.

CELADA, M. T. (2002). O espanbol para o brasileiro: uma língua singularmente estrangeira. Tesis de Doctorado en Lingüística. Instituto de Estudios del Lenguaje, Unicamp, Campinas.

CONSEJO DE EUROPA. (2002). Marco Común Europeo de Referencia para las Lenguas: aprendizaje, enseñanza, evaluación. España: Ministerio de Educación, Cultura y Deportes/Instituto Cervantes. Disponible en: https://cvc.cervantes.es/ensenanza/biblioteca_ele/marco/ cvc_mer.pdf. Acceso: 01 dic. 2017. 
CORACINI, M. J. (2007). A celebração do outro. Arquivo, memória e identidade: línguas (materna e estrangeira), plurilingüismo e tradução. Campinas: Mercado de Letras.

COSTA, J. M.; LACROZE, L. (2017). Cuántos extranjeros estudian en universidades argentinas y de qué países vienen. La Nación. 9 nov. 2017. Disponible en: https:// www.lanacion.com.ar/2071328-cuantos-extranjeros-estudian-en-universidadesargentinas-y-de-que-paises-vienen. Acceso: 14 abr. 2018.

DA ROSA, M. (2018). Seleção e ingresso de estudantes refugiados no ensino superior brasileiro: a inserção linguística como condição de hospitalidade. Trabalbos em Linguística Aplicada. v. 57, nº 3, pp. 1534-1551.

DERRIDA, J. (1996/2012). El monolingüismo del otro, o la prótesis de origen, trad. Horacio Pons. Buenos Aires: Manantial.

DERRIDA, J. (2000). Hostipitality. Angelaki: Journal of the theoretical bumanities. v. 5, $\mathrm{n}^{\mathrm{o}} 3$, pp. $3-18$.

DI TULliO, A. (2010). Politicas lingüísticas e inmigración: el caso argentino. Buenos Aires: Eudeba.

FRIGERIO, A. (2005). Migrantes exóticos: los brasileros en Buenos Aires. Runa. v. 25, nº 1, pp. $97-121$.

FREUD, S. (1919/1997). Lo ominoso. En: Obras completas [1917/1919], Tomo XVII. Buenos Aires: Amorrortu, pp. 215-251.

GAVIRA, M. (2017). Afirman que hay un récord de extranjeros en el CBC y una "ola brasileña" en Medicina. Clarín. 16 ago. 2017. Disponible en: https://www.clarin.com/ sociedad/afirman-record-extranjeros-cbc-ola-brasilena-medicina_0_rJD5W7b_b. html. Acceso: 27 mai. 2018.

GARCÍA CANCLINI, N. (2004). Diferentes, desiguales y desconectados: mapas de la interculturalidad. Barcelona: Gedisa.

KLETT, E. (2017). Internationalisation, plurilinguisme et formation des enseignants de langues étrangères. Synergies Argentine. no 5, pp. 57-70.

KRISTEVA, J. (1994). Estrangeiros para nós mesmos. Rio de Janeiro: Rocco.

LA CAPITAL. (2018). En tres años se triplicaron los ingresantes brasileños en Medicina. La Capital. 8 abr. 2018. Disponible en: https://www.lacapital.com.ar/la-ciudad/ 
en-tres-anos-se-triplicaron-los-ingresantes-brasilenos-medicina-n1586161.html. Acceso: 20 jun. 2018.

LUCHILO, L. (2018). Estudiantes internacionales: ċcosto o beneficio? Nuevos Papeles. 28 feb. 2018. Disponible en: http://www.nuevospapeles.com/nota/2100-estudiantesinternacionales-costo-o-beneficio. Acceso: 27 mai. 2018.

NARDONE, N. (2018). Rector de la UNR: "El ingreso no planificado de estudiantes extranjeros es un problema". VíaRosario. 28 nov. 2018. Disponible en: https://viapais. com.ar/rosario/729585-rector-de-la-unr-la-universidad-no-tiene-que-ser-una-fichaen-un-tablero-electoral/. Acceso: 5 mar. 2019.

ORLANDI, E. P. (2007). As formas do silêncio: no movimento dos sentidos, 6 a Ed. Campinas: Editora da Unicamp.

ORLANDI, E. P. (2015). Análise de discurso: princípios e procedimentos, $12^{\mathrm{a}}$ Ed. Campinas: Pontes.

ORLANDI, E. P. (2011). A linguagem e seu funcionamento: as formas do discurso, 6 a Ed. Campinas: Pontes.

PÊCHEUX, M. (1975/2016). Las verdades evidentes. Lingüística, semántica, filosofía, trad. Mara Glozman, $1^{\text {a }}$ Ed. Buenos Aires: Ediciones del CCC.

PÉREZ, L.; ROGIERI, P. (2013). Lengua nacional y lengua de inmigración en la política lingüística. Argentina (1880-1930). Revista Digital de Políticas Lingüísticas. v. 5, nº 5, pp. 99-117.

POZZO, M. I. (2014). La competencia comunicativa intercultural ante estudiantes haitianos de medicina: el caso de la Facultad de Ciencias Médicas de la Universidad Nacional de Rosario, Argentina. En: Soriano Ayala E.; González Jiménez A.; Cala V. (eds.), Retos actuales de Educación y Salud Intercultural. España: Universidad de Almería, pp. 92-102. Disponible en: http://www2.ual.es/eduhem2016/libros/retos1.pdf. Acceso: 10 jul. 2018.

RADIO EME. (2018). Invasión de brasileños en la Facultad de Medicina de Rosario. Radio Eme. 8 abr. 2018. Disponible en: http://www.radioeme.com/2018/04/invasion-debrasilenos-en-la-facultad-de-medicina-de-rosario. Acceso: 20 jun. 2018.

REVUZ, C. (1992). A língua estrangeira entre o desejo de um outro lugar e o risco do exílio. En: Signorini, I. (org.), Lingua(gem) e identidade: elementos para uma discussão no campo aplicado. Campinas: Mercado das Letras, 1998, pp. 213-230. 
RODRÍGUEZ, I. (2018). Español con fines académicos. Una experiencia de aprendizaje en las disciplinas. Comunicación oral en el Congreso Internacional del SICELE. 9 nov. 2018. Rosario: Universidad Nacional de Rosario.

ROTAETXE AMUSATEGI, K. (1990). Sociolinguiistica. Madrid: Editorial Síntesis.

UGARTECHE, S.; RODRÍGUEZ, J.; POZZO, M. I. (2012). Escenarios multiculturales en la universidad. De la tolerancia al valor de la diversidad. En: Actas de las Jornadas de Investigación en Psicología. Rosario: Secretaría de Ciencia y Técnica de la Facultad de Psicología de la Universidad Nacional de Rosario, pp. 313-319. Disponible en: http:// www.fpsico.unr.edu.ar/wp-content/uploads/2012/10/TEXTOCOMPLETOCD1. pdf. Acceso: 2 jul. 2018.

UNIVERSIDAD NACIONAL DE ROSARIO. (1989). Ordenanza No 490, del 28 nov. 1989. Consejo Superior.

UNIVERSIDAD NACIONAL DE ROSARIO. (2013). Boletín Estadístico n ${ }^{\circ} 64$, referente al año 2012. Disponible en: https://www.unr.edu.ar/noticia/1387/boletinesestadisticos. Acceso: 27 set. 2018.

UNIVERSIDAD NACIONAL DE ROSARIO. (2017). Ordenanza Nº 728, del 19 oct. 2017. Consejo Superior.

UNIVERSIDAD NACIONAL DE ROSARIO. (2018). Boletín Estadístico no ${ }^{\circ}$, referente al año 2017. Disponible en: https://www.unr.edu.ar/noticia/1387/boletinesestadisticos. Acceso: 27 set. 2018.

WLASH, C. (2010). Interculturalidad crítica y educación intercultural. En: Viaña, J.; Tapia, Li Walsh, C. Construyendo interculturalidad crítica. Bolivia: IIICAB, pp. 75-96.

Recebido: 22/04/2019

Aceito: 28/02/2020

Publicado: 10/03/2020 